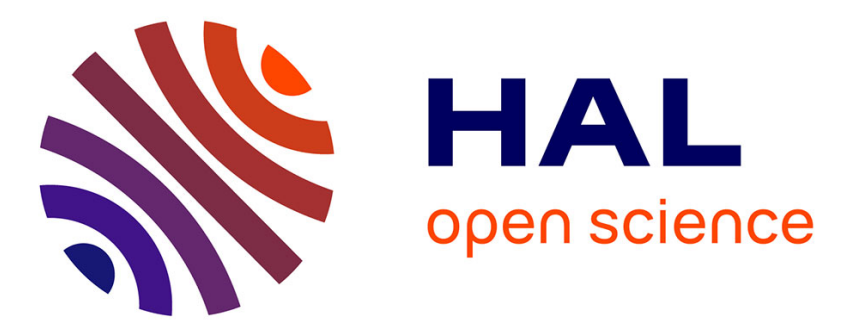

\title{
The DOAJ Ambassador Programme: An Example Project for Promoting Cognitive Justice in the Global South
}

\author{
Tom Olyhoek, Barbara Porrett, Dominic Mitchell
}

\section{- To cite this version:}

Tom Olyhoek, Barbara Porrett, Dominic Mitchell. The DOAJ Ambassador Programme: An Example Project for Promoting Cognitive Justice in the Global South. ELPUB 2018, Jun 2018, Toronto, Canada. 10.4000/proceedings.elpub.2018.13 . hal-01816632

\section{HAL Id: hal-01816632 \\ https://hal.science/hal-01816632}

Submitted on 15 Jun 2018

HAL is a multi-disciplinary open access archive for the deposit and dissemination of scientific research documents, whether they are published or not. The documents may come from teaching and research institutions in France or abroad, or from public or private research centers.
L'archive ouverte pluridisciplinaire HAL, est destinée au dépôt et à la diffusion de documents scientifiques de niveau recherche, publiés ou non, émanant des établissements d'enseignement et de recherche français ou étrangers, des laboratoires publics ou privés.

\section{(c)(1)}

Distributed under a Creative Commons Attribution| 4.0 International License 


\title{
The DOAJ Ambassador Programme: An Example Project for Promoting Cognitive Justice in the Global South
}

\author{
Tom Olyhoek, Barbara Porrett and Dominic Mitchell
}

\section{Introduction}

1 The Directory of Open Access journals (DOAJ) was founded in 2003 as a list of good quality Open Access journals. What began as a list of a few hundred journals has grown into an index containing $>11,000$ journals. Although the DOAJ index already contains entries from many countries we felt an urgent need to expand it with more journals from the Global South. In our view this was a necessary step in order to continue to serve as the comprehensive global whitelist of trustworthy open access journals and as a comprehensive index of $\mathrm{OA}$ journals for authors, researchers, librarians and publishers (Stenson, 2011). Inclusion of these journals will serve to increase the visibility and access to scientific knowledge from the Global South. It will also serve to combat cognitive injustice. When local knowledge is less accessible and marginalized in the global scientific output by virtue of the pressure on scientists to publish preferentially in English language journals from the Global North, cognitive injustice occurs (Hall \& Tandon, 2017; Piron et al., 2016).

2 For this reason the DOAJ started the Ambassador programme in 2016. A team of scholars from the developing world (the Ambassadors) were trained to evaluate open access journals from their regions and to assist local publishers in meeting the requirements of good publishing practice. Other successful ambassador programs for the promotion of education and teaching had already been established by EIFL and COS (Center for Open Science). Additional organizations are seeking to set up their own programmes. To the best of our knowledge, the DOAJ initiative to employ ambassadors in the Global South for the promotion of open access publishing and the evaluation of local journals is unique. 
With the help of the Ambassador programme, all questionable journals, many of from developing world regions (Thomas, 2015; Jones, 2015), have now been removed from DOAJ. Many other journals were also removed, during a two year period, for not meeting the DOAJ criteria. During that time, all existing journals in the database were reevaluated using the newly developed set of criteria (Adams, 2015; Van Norden, 2014; Olijhoek et al., 2016). The Ambassadors and local voluntary editorial teams have been instrumental in completing this process successfully. In addition, their work has increased the coverage of open access journals from their respective regions in DOAJ. Currently Ambassadors and local teams are identifying the publishers of credible journals in their respective region, guiding them to meet the criteria of best publishing practice and encouraging these journals to apply for indexing in the DOAJ.

\section{Setting up the Ambassador programme}

\section{Selection}

The project required Ambassadors to engage in the following tasks:

- Identify tools other than the DOAJ that assist in making informed decisions about where to submit articles for publication (based in part on the ThinkCheckSubmit initiative) and share case studies and examples gathered by DOAJ in over thirteen years of operation.

- Evaluate journals for inclusion in the Directory based on a set of criteria developed to identify and promote best publishing practice, transparency and high editorial quality. The criteria for inclusion in the DOAJ are an integral part of the application form (DOAJ Application Form, https://doaj.org/application/new, accessed 26 March 2018).

- Liaise with publishers and academics in their own countries/regions and advise them on the importance of best practice, transparency and high editorial quality.

- Promote OA publishing in the "Global South", as defined in an IDRC list of 85 countries in 10 regions with an Ambassador for each region. (Countries covered by each Regional Ambassador, DOAJ document, http://bit.ly/2DV2J5K, accessed 26 March 2018).

5 The IDRC list of countries and regions was broken down into 7 areas (Table 1-See bellow) based on the distribution of the 2,500 applications or re-applications from journals from developing countries in the DOAJ index at the start of the project. Candidates to serve as Ambassadors were identified from existing lists of contacts, crowdsourced from partner organizations and requested in a blog post announcement (IDRC grant to improve OA journals from the Global South, DOAJ Blog, http://bit.ly/2DTCT24, accessed 26 March 2018).

6 Twelve trustworthy, reputable and dedicated individuals were interviewed and identified to become DOAJ Ambassadors. Selection was based on experience, language skills and connectivity. Interviews were conducted online and references were then checked. The locations of the successful candidates resulted in an adjustment to the breakdown of regions to match the geographic distribution of the selected Ambassadors (Table 2-See bellow). 
Table 1. The initial breakdown of regions and languages, based on the IDRC list, before interviewing candidates and making appointments

\begin{tabular}{|l|l|}
\hline Region & Language \\
\hline Latin America & Spanish and/or Portuguese \\
\hline Middle East \& Persian Gulf & Arabic \\
\hline Africa (North/West) & Arabic and French \\
\hline Africa (South/East) & English \\
\hline India/Pakistan & Hindi \\
\hline Indonesia & Indonesian \\
\hline China & Chinese (Mandarin or Cantonese) \\
\hline
\end{tabular}

Table 2. The breakdown of regions and language, and the number of Ambassadors for each region

\begin{tabular}{|l|l|}
\hline Region & Number of Ambassadors \\
\hline Latin America (Spanish/Portuguese) & 1 \\
\hline NW Africa \& Middle East (Arabic \& French) & 3 \\
\hline Africa (South and East) (English) & 2 \\
\hline India (English) & 3 \\
\hline China (Chinese) & 3 \\
\hline *Russia & 3 \\
\hline$* *$ Indonesia & 4 \\
\hline$* *$ South-East Asia & 4 \\
\hline
\end{tabular}

* Upon hearing about the Ambassador program from a presentation made by Tom Olijhoek in May 2016, DOAJ was approached by the President of the Russian Association of Science Editors and Publishers, requesting that Russia be included in the programme. The President was impressed by the potential impact that such a project could have and wanted very much to see the same impact in Russia. As a result, three Russian Ambassadors also joined the programme with funding from their own organizations.

${ }^{*}$ Indonesia and South Korea have been included in the Ambassador programme since 2017. After conducting training sessions in each country, four Ambassadors were selected from each region.

7 The DOAJ currently has 23 Ambassadors worldwide. Their positions and backgrounds are diverse: from $\mathrm{PhD}$ student to professor, a librarian to head of a university library, and from library and informatics specialist to senior manager in a publisher organization. Equally, the ages of the Ambassadors range between 30 and 60. The group consists of 12 
women and 11 men. Their biographies are available on the DOAJ website (https:// doaj.org/about\#ambassadors).

\section{Training}

8 An initial training session took place on the Greek island of Crete in June 2016. The Ambassadors were taught how to process applications and reapplications with documentation and tools provided by DOAJ staff. The training included sessions on communication skills, cultural differences, questionable publishing, open access publishing and copyright and licensing. The training on cultural differences proved to be particularly useful. It guided the communication between DOAJ staff, who are based in different countries in Western Europe and the Ambassadors with their various cultural backgrounds. Working with diverse groups requires different approaches and methodologies for education and group management (Meyer, 2014).

9 After the training, the Ambassadors had access to recordings of the training sessions. Subsequent communications took place via Skype, Google Hangouts, WebEx etc. and training on expert topics like open access licensing was continued online.

The Ambassadors were tasked with handling existing applications from their own countries/regions. They have communicated with those submitting applications to DOAJ, raised awareness around open access and open science and operated proactively as a "helping hand" for the applicants. Each Ambassador had a dedicated DOAJ team member allocated as their supervisor. The supervisor participated in continued training online and worked with the Ambassador in the processing of applications to ensure that they could carry out their duties effectively. The Ambassadors' performance was monitored via the DOAJ administration system which is used for all application-related transactions. During the entire project, the DOAJ team have facilitated the exchange of experiences and challenges through regular online meetings with all Ambassadors.

\section{Outreach}

11 The Ambassadors collaborated with DOAJ staff to tailor generic presentations (often in local language) to meet local needs. These were presented by them at relevant events in their country or region. Opportunities for outreach were identified in collaboration with the Ambassadors and partner organizations (EIFL, ISSN, INASP etc.). These included publisher events, academic library events and events at universities and research institutions. Translation of relevant information pages of the DOAJ website and of flyers and posters was undertaken by Ambassadors in close cooperation with DOAJ staff. Having this information available in local languages proved enormously valuable to the work of the Ambassadors.

12 The Ambassadors have reached out to communities in their regions and general information has been pushed out via the various channels available-the DOAJ website and partner organizations like EIFL, Research for Life (R4L), ISSN, and social media channels (Facebook, Twitter, and Chinese social media platforms etc.). 


\section{Results} journals from developing countries were reviewed with the help of local Ambassadors. Partner programmes led by Ambassadors have carried out OA publishing training for local publishers. The impact of the training on DOAJ usage is shown in Figure 1. Overall usage of the DOAJ from the Global South has increased with 21\% from 2015 to 2016 and with $41 \%$ from 2016 to 2017. It must be acknowledged that increased awareness of open access worldwide could have contributed to this change. However, the scale of the increase and the number of promotional activities undertaken by the Ambassadors suggest that there is a positive correlation between the high growth rate of usage and the DOAJ Ambassador programme.

In addition, the DOAJ Ambassadors have made more than 100 contributions/ presentations at local conferences and events, where the knowledge they have acquired during the project was disseminated. DOAJ assisted, where needed, in creating presentations for the Ambassadors at regional conferences and assisted in writing papers/social media contributions from the Ambassadors.

Figure 1. Increased usage of DOAJ by users in the Global South after starting the ambassador programme. The size of the dots is proportional to the amount of increase

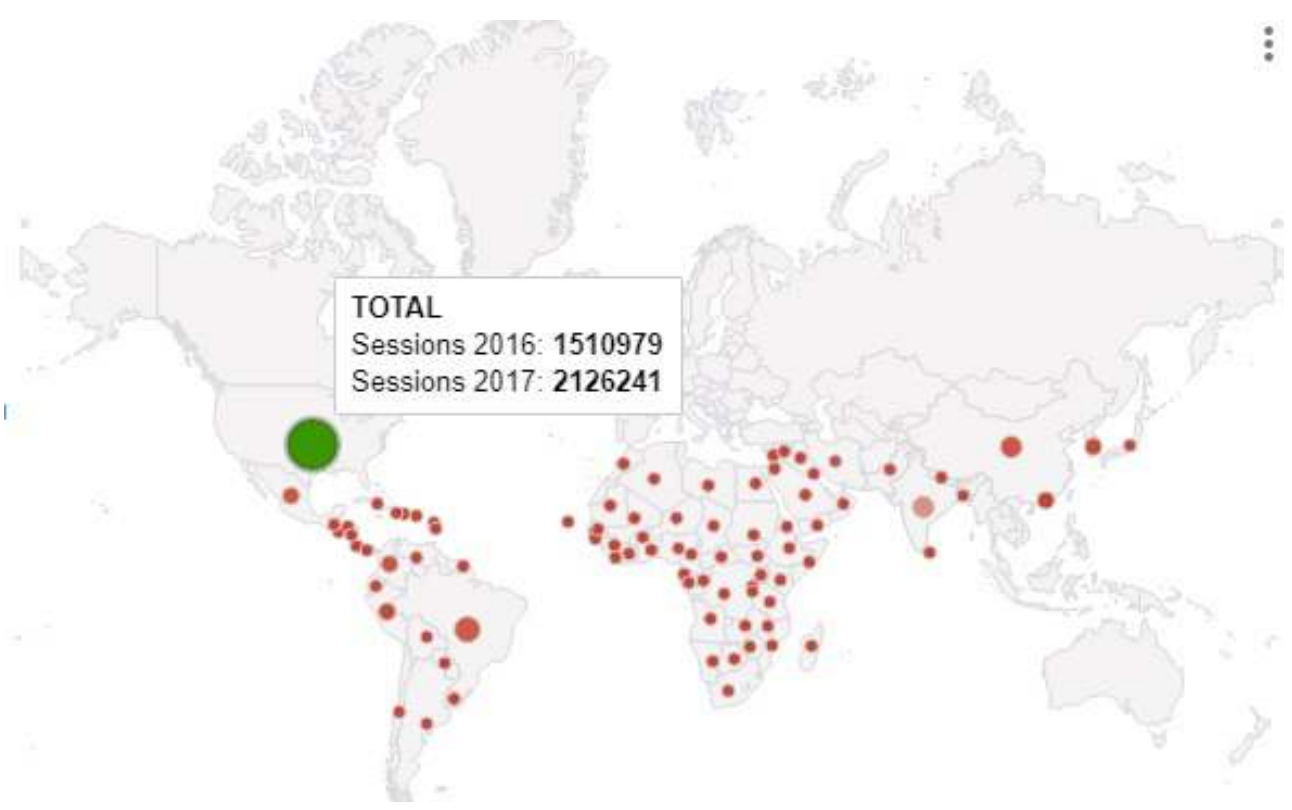


Figure 2. Events where DOAJ Ambassadors participated. (An extract for Latin America. The full document is available on request.)

\begin{tabular}{|l|l|l|}
\hline Event & Type & Audience \\
\hline $\begin{array}{l}\text { Academic Journals Editors Regional Meeting, } \\
\text { Medellin, Colombia }\end{array}$ & Presentation & $\begin{array}{l}\text { researchers, librarians \& policy } \\
\text { makers }\end{array}$ \\
\hline $\begin{array}{l}\text { Meeting with Caicyt Information Professionals, } \\
\text { Buenos Aires, Argentina }\end{array}$ & Talk & librarians \& policy makers \\
\hline $\begin{array}{l}\text { UNAM Permanent Seminar of Editors, Mexico } \\
\text { City, Mexico }\end{array}$ & Presentation & $\begin{array}{l}\text { researchers, librarians \& policy } \\
\text { makers }\end{array}$ \\
\hline $\begin{array}{l}\text { Professionalization of Scholarly Journals, } \\
\text { SciELO, Brazil }\end{array}$ & Talk & $\begin{array}{l}\text { researchers, } \\
\text { students \& policy makers }\end{array}$ \\
\hline INFO Conference 2016, La Habana, Cuba & Workshop & librarians \& policy makers \\
\hline
\end{tabular}

Table 3. Profiles of three Ambassadors with extracts from their CVs, their main achievements during the project and the country or region where they are based

\begin{tabular}{|c|c|}
\hline $\begin{array}{l}\text { Kamel Belhamel: } \\
\text { North Africa }\end{array}$ & $\begin{array}{l}\text { Kamel holds a PhD from the University of Setif (Algeria) in Chemical } \\
\text { Process Engineering. He is now Professor of Chemistry at University of } \\
\text { Bejaia, Director of the Laboratory of Organic Materials and Editor in chief } \\
\text { of DOAJ-indexed Algerian Journal of Natural Products (ISSN: 2353-0391). He } \\
\text { is the author of several publications and communications in the field of } \\
\text { Chemical Process Engineering, Natural Products, Nanoparticles and } \\
\text { Metal Alloys. Kamel has long, international experience in the } \\
\text { management of Research Projects (Projects DAAD German, French } \\
\text { Framework Programme CMEP...) and Coordinator of two Algerian } \\
\text { Research projects CNEPRU, PNR...). Kamel is the DOAJ Ambassador in } \\
\text { region of North Africa. }\end{array}$ \\
\hline $\begin{array}{l}\text { Major } \\
\text { achievements }\end{array}$ & $\begin{array}{l}\text {-Events: } 3 \text { talks, attendance at several conferences } \\
\text {-Applications: processed over } 200 \text { applications. } \\
\text {-Other: Helped Algeria's government to require open access publishing } \\
\text { for all scientists at Algerian universities. }\end{array}$ \\
\hline
\end{tabular}




\begin{tabular}{|l|l|}
\hline Leena Shah, India & $\begin{array}{l}\text { Leena Shah holds a Master's Degree in Information Studies from Nanyang } \\
\text { Technological University (NTU), Singapore and a Bachelor's degree in } \\
\text { Engineering. After living and working for nearly two decades in Singapore } \\
\text { she relocated to Bangalore, India, in May } 2016 \text { and is keen on promoting } \\
\text { Open Access in this region. She was previously employed as an Earth } \\
\text { Sciences Librarian at NTU where she gained experience in teaching and } \\
\text { promoting open access, institutional repositories and scholarly } \\
\text { communication in general to researchers and students. Leena is one of } \\
\text { three DOAJ Ambassadors for India. }\end{array}$ \\
\hline Major \\
achievements
\end{tabular}

\begin{tabular}{|l|l|}
\hline $\begin{array}{l}\text { Ivonne Lujano, } \\
\text { Latin America }\end{array}$ & $\begin{array}{l}\text { Ivonne has a Master's in Social Sciences with an emphasis in Education at } \\
\text { FLACSO-Argentina and holds a B.A. in Education from the Universidad } \\
\text { Autónoma del Estado de México (UAEMex), where she currently works as } \\
\text { lecturer. She is specialized in scientific Open Access publishing processes } \\
\text { and has experience in the evaluation of scholarly publishing practices. } \\
\text { She has worked with institutions and organizations at a national and } \\
\text { regional level in the training of students, teachers and researchers on } \\
\text { issues regarding scientific publishing in Open Access. Ivonne is the DOAJ } \\
\text { Ambassador for the region of Latin America. }\end{array}$ \\
\hline $\begin{array}{l}\text { Major } \\
\text { achievements }\end{array}$ & $\begin{array}{l}\text {-Events: } 5 \text { presentations, } 10 \text { talks and workshops. } \\
\text {-Applications: processed over } 300 \text { applications }\end{array}$ \\
\hline
\end{tabular}

15 A major lesson that the DOAJ team learnt from the Ambassador programme is the difficulties of explaining the concepts of open access to Ambassadors, and then by the Ambassadors to their local contacts. The team has also observed that where Ambassadors have worked with governments to increase awareness, the commitment to open access principles has been strengthened. For example:

1. After working closely with the DOAJ Ambassador Prof. Kamel Belhamel, the Algerian government has required open access publishing by all scientists at Algerian universities.

2. An Indonesian organization of professors and university lecturers called ADRI has been instrumental in recruiting Ambassadors for the country and for establishing contacts with the Indonesian government. The government recognizes journals listed in the DOAJ as accredited journals and Indonesian scientists can earn merits when they publish in these OA journals.

These examples illustrate the importance of making higher level connections either through the local DOAJ Ambassadors, or through organizations that have solicited collaboration with the DOAJ. 
17 To help increase awareness and the uptake of best practice even further, the DOAJ team developed an online resource, the DOAJ Best Practice Guide (http:// www.doajbestpracticeguide.org/. It provides information about best practice in scholarly publishing and guidance on to how to identify questionable publishing practices. This resource was developed with existing and new information from the Ambassador programme. The resource will support the future work of the Ambassadors as well as academics, librarians and publishers worldwide. Based on the information provided on the For Publishers pages of the DOAJ website, and the Principles of Transparency and Best Practice in Scholarly Publishing-it is intended to achieve the following:

- Highlight the issue of questionable publishing practices.

- Provide a checklist of criteria to identify questionable publishers (based on guidelines for editors working with applications to DOAJ).

- Identify other tools that assist in making informed decisions about where to submit articles for publication (based in part on the ThinkCheckSubmit initiative), and share case studies and examples gathered by DOAJ in over thirteen years of operation.

The DOAJ Best Practice Guide is curated and regularly updated as part of the general operations at DOAJ.

Figure 3 shows the increase in the number of journals from the Ambassador regions of Table 2. The results were obtained from the DOAJ administration system. It shows that the number of accepted journals from the Global South had double the growth rate observed for journals from the rest of the world. Like Figure 1, this illustrates the effectiveness of the Ambassador programme.

Figure 3. Increase in number of accepted journals in the DOAJ from the Global South compared with the rest of the world between Nov 2015 and Jan 2017

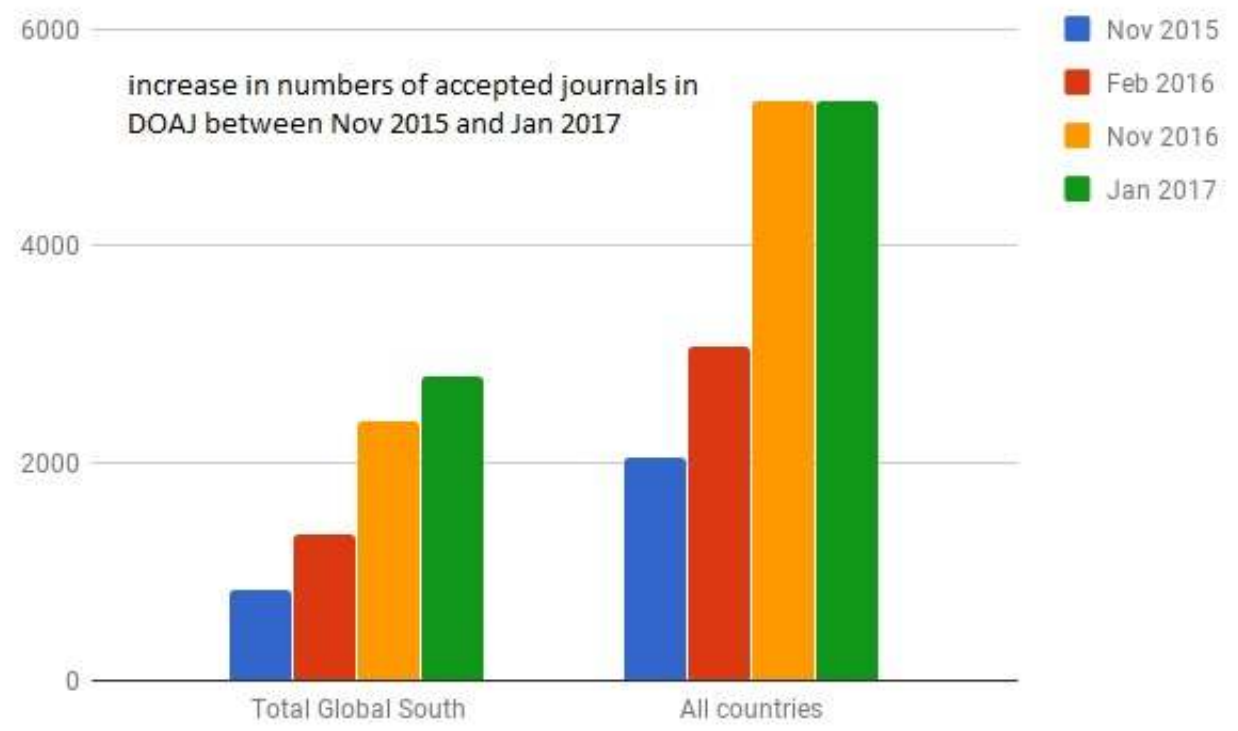

\section{Conclusions and Future developments}

The participation of local Ambassadors and voluntary editorial team members was critical to the programme's efforts to combat cognitive injustice. Knowledge of the local 
context and contacts with the regional academic community, government and publishers were essential prerequisites. The Ambassadors developed an accurate understanding of how open access journal publication was perceived in their countries. With this knowledge they were able to disseminate information about open access that was sensitive to regional culture and local requirements. Most critically, communication was done in local languages. This, we suggest, facilitated the project's rapid progress. The DOAJ is convinced that it could not have achieved as much in such a relatively short time without the help of the developing world team. A lack of knowledge about open access licensing and copyright in the South and the absence of information in the literature and on the web about open access in languages other than English were impediments. Despite this, the project accomplished the following:

- The infrastructure to support open access publishing in the Global South has been enhanced.

- The visibility of open access journals from the developing world has been improved.

- The risk of developing world researchers publishing with questionable publishers has decreased.

- Knowledge about good open access publishing practices has been enhanced among developing world publishers and a group of developing world academics by providing translations to information on Open Access publishing.

- Awareness about the DOAJ in the South has been enhanced.

- Statistics illustrating the objectives met are presented as part of this paper. (Figure 1 \& Figure 3).

- The DOAJ Best Practice Guide was realized.

The DOAJ's efforts to support cognitive justice for Southern researchers continue. We are discussing collaboration with a similar ambassador programme that Crossref wants to build. We are also talking with Creative Commons representatives on possibilities to have our DOAJ Ambassadors promote Creative Commons in their regions.

\section{BIBLIOGRAPHY}

\section{References}

Adams, C. (2015, March 5). Directory of Open Access Journals introduces new standards to help community address quality concerns [Blog post]. Retrieved from http://sparc.arl.org/blog/doajintroduces-new-standards

Hall, B.L., \& Tandon, R. (2017). "Decolonization of knowledge, epistemicide, participatory research and higher education." Research for All, 1(1): 6-19. Retrieved from https:// doi.org/10.18546/RFA.01.1.02 Jones, P. (2015, July 29). Predatory publishing isn't the problem, it's a symptom of information inequality [Blog post]. Retrieved from https://www.digital-science.com/blog/perspectives/predatorypublishing-isnt-the-problem-its-a-symptom-of-information-inequality/ 
Meyer, E. (2014). The culture map: decoding how people think, lead and get things done across cultures. Philadelphia, PA : Perseus Books Group.

Olijhoek, T., Mitchell, D., \& Bjørnshauge, L. (2015, November 16). "Criteria for open access and publishing." ScienceOpen Research. Retrieved from https://www.scienceopen.com/document/ vid/2befee62-f9c0-4dc8-93c5-790d6102877d?0

Piron, F., Regulus, S., \& Dibounje Madiba, M. (2016, December). Justice cognitive, libre accès et savoirs locaux. Pour une science ouverte juste, au service du développement local durable. Québec, QC : Éditions science et bien commu. https://doi.org/10.5281/zenodo.205145

Stenson, L. (2011). “The development of Directory of Open Access Journals.” ScieCom Info, 7(1). Retrieved from http://journals.lub.lu.se/index.php/sciecominfo/article/view/4912

Thomas, A. (2015, October 29). African academics are being caught in the predatory journal trap [Blog post]. Retrieved from https://theconversation.com/african-academics-are-being-caught-in-thepredatory-journal-trap- 48473

Van Norden, R. (2014). "Open Access web site gets tough: leading directory tightens listing criteria to weed out rogue journals." Nature, 512(7512). Retrieved from http://www.nature.com/ news/open-access-website-gets-tough-1.15674

\section{ABSTRACTS}

Global scientific publishing, including open access publishing, is heavily biased towards journals and authors from the Global North. This has resulted in a knowledge gap between the South and the North. It has led to a situation where scientific knowledge from the Global South is very much underrepresented in the collective scientific output worldwide: a problem which has been described as cognitive injustice. Unfortunately this situation is not helped by the fact that many questionable publishers are based in countries in the Global South. To address these issues the Directory of Open Access Journals (DOAJ) started an Ambassador programme in 2016 with the help of funding from the International Development Research Centre (IDRC Canada). The main objective of the programme was to increase the number of quality open access journals published, and the quality of open access publishing, in the Global South.

questionable journals, questionable publishers, cognitive justice, Global South, Directory of Open Access Journals, Ambassadors

\section{AUTHORS}

\section{TOM OLYHOEK}

DOAJ Editor in Chief, Netherlands

tom@doaj.org

https://orcid.org/0000-0002-5433-5944

\section{BARBARA PORRETT}

DOAJ Ambassador, Canada

porrettbarbara1@gmail.com

https://orcid.org/0000-0001-8316-3478

(corresponding author) 


\section{DOMINIC MITCHELL}

DOAJ Operations Manager, Sweden

dominic@doaj.org

https://orcid.org/0000-0003-2432-7035 